\title{
Control System of Underwater Vehicle Based on Artificial Intelligence Methods
}

\author{
Piotr Szymak and Józef Małecki \\ Polish Naval Academy \\ Poland
}

\section{Introduction}

One of the main development directions of an underwater technology are robots, which are working under the surface of a water. Using of these unmanned vehicles enables exploration at bigger depths and in more hazardous conditions (Kubaty \& Rowiński, 2001). Correctness of realization of different underwater works requires precise control of robot's movement in underwater environment.

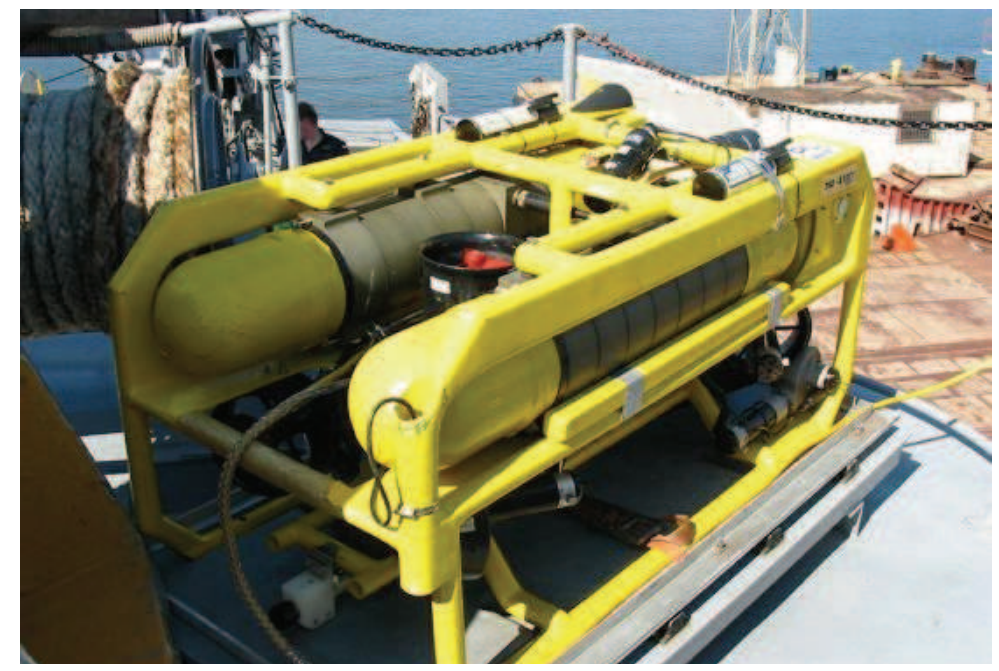

Fig. 1. Remotely operated vehicle called Ukwial

In the case of underwater robot is object of nonlinear dynamics and works in marine environment with different disturbances robust nonlinear control method may be applied. An example of this kind application is designed and verified automatic control system of underwater vehicle called Ukwial (fig. 1).

Problem of underwater vehicle's control is considered by several scientific centers (particularly in the United States - Florida Atlantic University, Massachusetts Institute of Technology, Naval Postgraduate School in Monterey; in Japan - Osaka University, in 
Norway - University of Trondheim, in Poland - Szczecin University of Technology, Polish Naval Academy in Gdynia). Direct results of researches are usually inaccessible for the sake of their commercial or military application. While published results of researches are concerned mainly on basic problems: control of course and control of draught.

This chapter contribute into domain of underwater vehicle's control results of numerical and experimental researches of remotely operated vehicle Ukwial, which is used in Polish Navy. Using of presented robust nonlinear control method helps operators of Ukwial in their daily work.

In the chapter selected aspects of steering an underwater vehicle along desired trajectory have been developed. The fuzzy data processing has been applied for compensation of the nonlinear underwater vehicle's dynamics and influence of environmental disturbances. It has enabled to calculate command signals driving the vehicle with set values of movement's parameters. An architecture of the selected fuzzy logic controllers has been presented. Moreover, the results of computer simulations and experimental research of remotely operated vehicle Ukwial have been inserted.

\section{Mathematical model of an underwater vehicle}

Nonlinear model in six degrees of freedom has been accepted to simulate movement of the underwater vehicle (Fossen, 1994). This movement has been analyzed in two coordinate systems:

1. the body-fixed coordinate system, which is movable,

2. the earth-fixed coordinate system, which is immovable.

While for the aim of movement description, notation of physical quantities according to SNAME (The Society of Naval Architects and Marine Engineers) has been accepted. Underwater vehicle's movement is described with the aid of the six equations of motion, where the three first equations represent the translational motion and the three last equation represent the rotational motion. These six equations can be expressed in a compact form as:

$$
\mathrm{M} \dot{v}+\mathrm{C}(v) v+\mathrm{D}(v) v+\mathrm{g}(\eta)+\mathrm{U}(v) v=\tau
$$

Here $v=[u, v, w, p, q, r]$ is the body-fixed linear and angular velocity vector, $\eta=[x, y, z, \phi, \theta, \psi]$ is the earth-fixed coordinates of position and Euler angles vector and $\tau=[X, Y, Z, K, M, N]^{T}$ is the vector of forces and moments of force influenced on underwater vehicle. $M$ is a inertia matrix, which is equal a rigid-body inertia matrix and added mass inertia matrix. $C$ is a Coriolis and centripetal matrix, which is a sum of rigid-body and added mass Coriolis and centripetal matrixes. $\mathrm{D}$ is a hydrodynamic damping matrix and $\mathrm{g}$ is a restoring forces and moments matrix. $U$ is a damping matrix generated by a cable called an umbilical cord. Underwater vehicle is supplied and can be controlled via the umbilical cord.

After making assumption that underwater vehicle has three planes of symmetry, it moves with small speed in a viscous liquid and an origin of movable coordinate system covers with vehicle's centre of gravity, specific form of matrixes with nonzero values of diagonal's elements has been obtained (Fossen, 1994). According to earlier researches (Szymak \& Małecki, 2007) these elements were calculated on the base of geometrical parameters of remotely operated vehicle (abbr. ROV) Ukwial.

Whereas Coriolis and centripetal matrixes were omitted because of small numerical values, unimportant in computer simulation. 
Nonlinear mathematical model of an underwater vehicle has been considered in more detail in (Fossen, 1994).
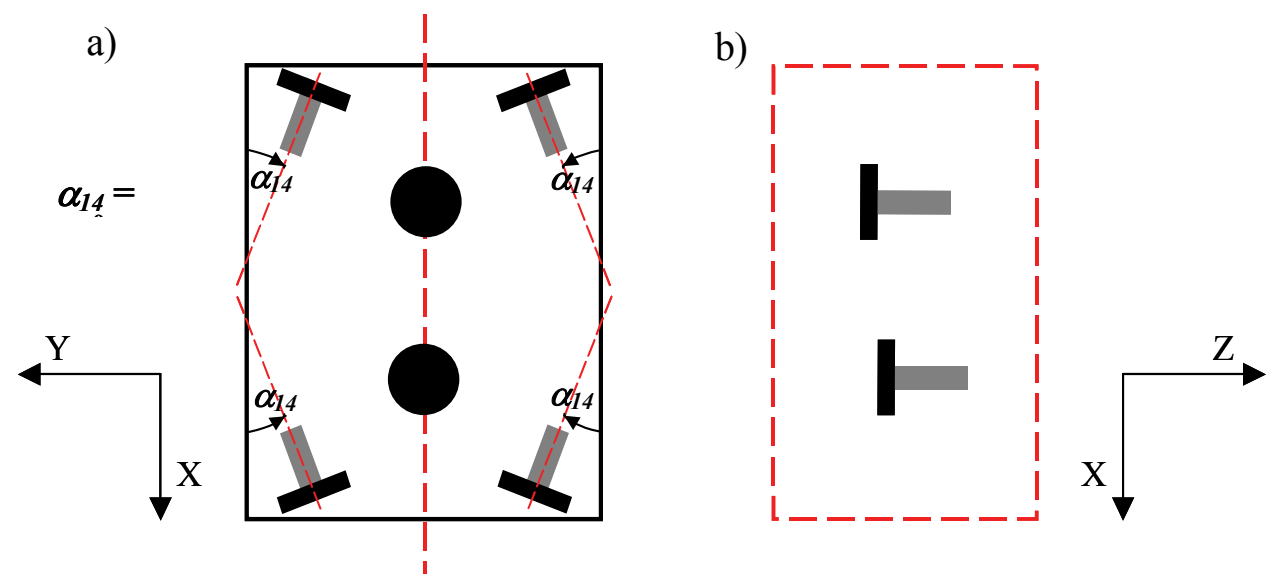

Fig. 2. Location of particular Ukwial's propellers in: a) horizontal and b) vertical plane

ROV Ukwial was designed in Underwater Technology Department from Gdansk University Of Technology. It is remotely operated and powered from board. A construction of Ukwial is based on cubicoid-shape frame, where all propulsion system and added equipment are mounted to the frame. This underwater vehicle has specific propulsion system, consisted of: four, three blade screw propellers in horizontal plane (fig. 2, here $\alpha_{14}=29^{\circ}$ ) and two, three blade screw propellers in vertical plane. Each propeller is electrically driven.

Presented propulsion system enables to move underwater vehicle in water with average speed 0,5-1,0 m/s and allows to control ROV's movement in five degrees of freedom (three translations motions: in longitudinal axis of symmetry $\mathrm{x}_{\mathrm{o}}$, in lateral axis of symmetry $\mathrm{y}_{\mathrm{o}}$ and in vertical axis of symmetry $z_{0}$, and two rotations around lateral axis of symmetry $y_{o}$ and around $\mathrm{z}_{\mathrm{o}}$ axis).

Moreover specific location of propellers in horizontal plane (at an angle of $29^{\circ}$ to the longitudinal axis of symmetry) gives possibility of steering this ROV in case of one of propellers is out of order.

\section{Architecture of Ukwial's control system}

Designed automatic control system of underwater vehicle consists of (fig. 3):

1. supervisory control unit, which is responsible for setting values of movement's parameters, turning on and off individual controllers at the proper moments,

2. the four controllers of: course, displacement in $X$ axis, displacement in $Y$ axis and draught, which generate adequate control signals: moment of force $N$, force in $\mathrm{X}$ axis, force in $Y$ axis and force $Z$.

Proportional-derivative action controllers based on the fuzzy logic have been applied to carry out control of course, displacement in $\mathrm{X}$ axis, displacement in $\mathrm{Y}$ axis and draught (fig. 4), where parameter $p$ is adequate course, coordinate $x, y$ or $z$.

Using of fuzzy logic method in FPD controllers depends on selection (Driankov et al., 1996): 
1. number, type and position's parameters of membership function of the input and output variables,

2. fuzzy inference rules, which create base of rules.

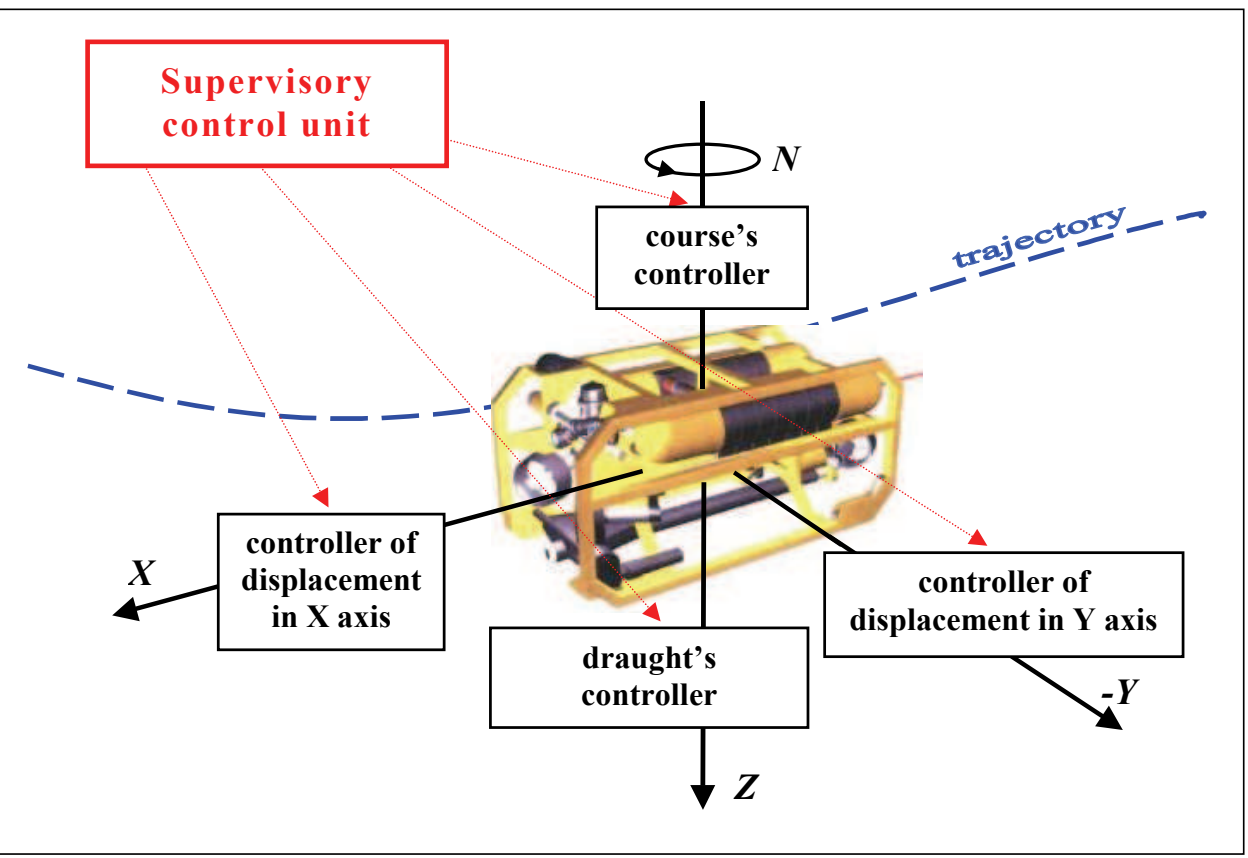

Fig. 3. Automatic control system of underwater vehicle called Ukwial

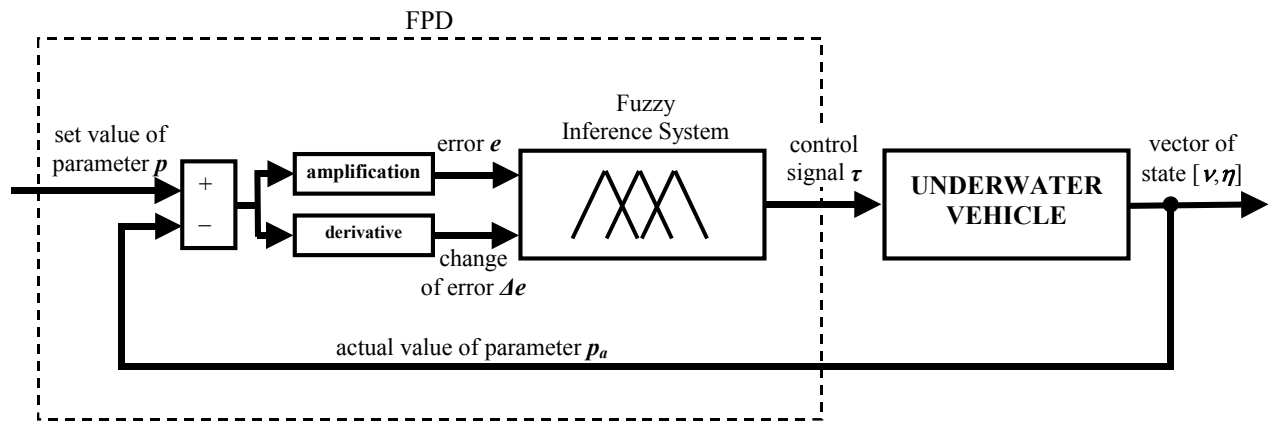

Fig. 4. Block diagram of fuzzy proportional-derivative controller FPD

Membership functions for linguistic input variables: error signal and derived change in error and output variable - control signal were tuned with the aid of the mathematical model simulation of the automatic controlled underwater vehicle. Direct and integral indexes were used to evaluate control quantity of designed control system. Results of this selection method for course controller have been presented in fig. 5 . 
Presented membership functions selection allow to create base of 35 rules (fig. 6). Particular rule could be read from the intersection of specified row and column. For the first row and first column following rule has been obtained:

If error of course is Negative Large and change in error of course is Negative Large

then moment of force $N$ is Negative Large

Rules from the Mac Vicar-Whelan's standard base were chosen as the control rules (Garus \& Kitowski, 2001).
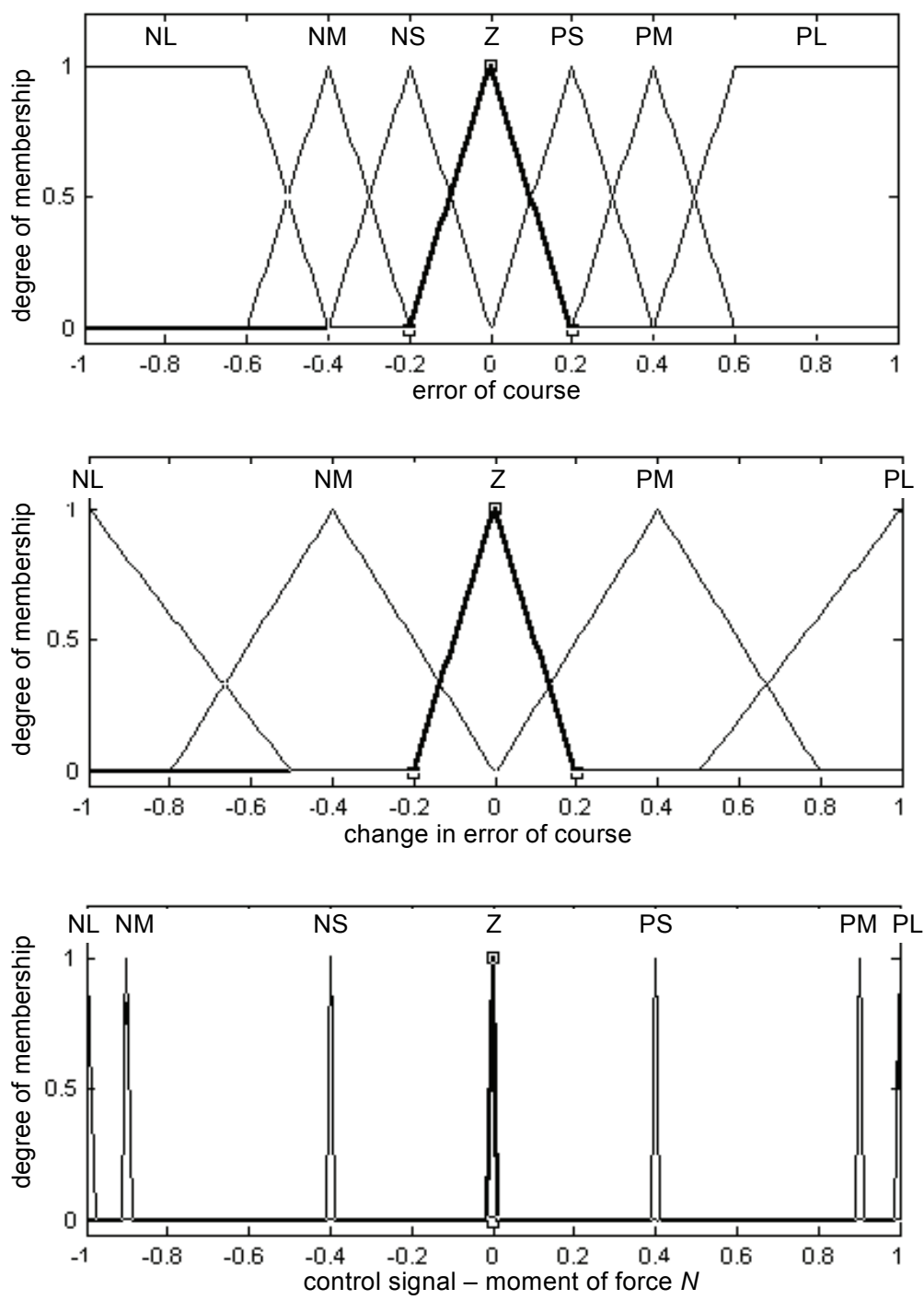

Fig. 5. Fuzzy partition of the universe of discourse of course 


\begin{tabular}{|c|c|c|c|c|c|c|c|c|}
\hline & \multicolumn{7}{|c|}{ error of course } \\
\hline & & NL & NM & NS & Z & PS & PM & PL \\
\hline \multirow{5}{*}{ 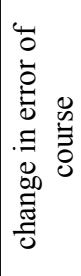 } & NL & NL & NL & $\mathrm{NL}$ & $\mathrm{NM}$ & $\mathrm{Z}$ & PS & PL \\
\hline & NS & NL & NL & NM & NS & PS & PM & PL \\
\hline & Z & NL & $\mathrm{NM}$ & NM & Z & PM & PM & PL \\
\hline & PS & NL & $\mathrm{NM}$ & NS & PS & PM & PL & PL \\
\hline & PL & NL & NS & Z & PM & PL & PL & PL \\
\hline
\end{tabular}

Fig. 6. Base of rules of course controller (NL - Negative Large, NM - Negative Mean, NS Negative Small, Z - zero, PS - Positive Small, PM - Positive Mean, PL - Positive Large)

\section{Results of numerical researches}

Computer simulations were carried out in the Matlab environment on the platform computer PC / Windows XP. At the beginning each controller was tuned with the aid of direct and integral control quantity indexes.

Subsequently whole automatic control system of underwater vehicle Ukwial (fig. 3) was tested. Researches were carried out in simulated underwater environment with or without an influence of sea current with defined parameters: $V_{p}$ (velocity) and $\alpha_{p}$ (an angle between magnetic north and direction of affecting in horizontal plane).

Tested task of designed control system was to steer the underwater vehicle along desired trajectory in vertical plane $\mathrm{XZ}$ (fig. 7).
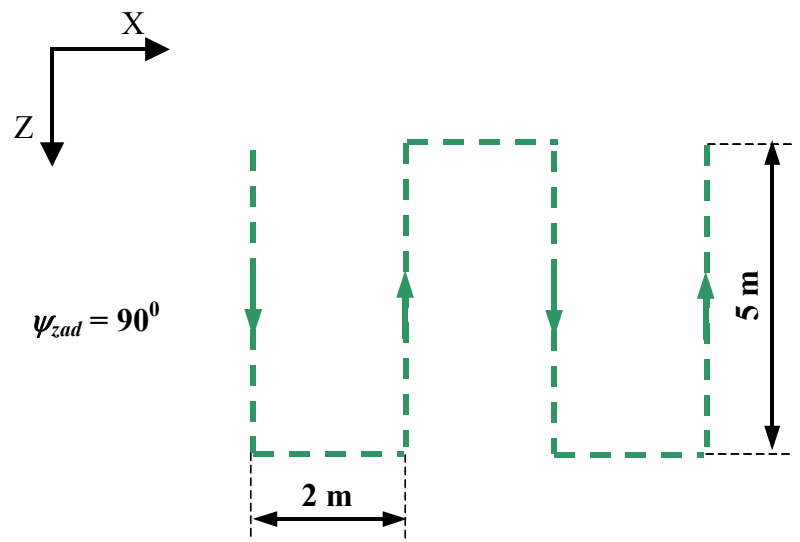

Fig. 7. Desired trajectory of Ukwial in vertical plane

Presented course of desired trajectory (fig. 7) comes from nature of the mission executed by the underwater vehicle, which is inspection of hull's part located below surface of water (fig. 8). 


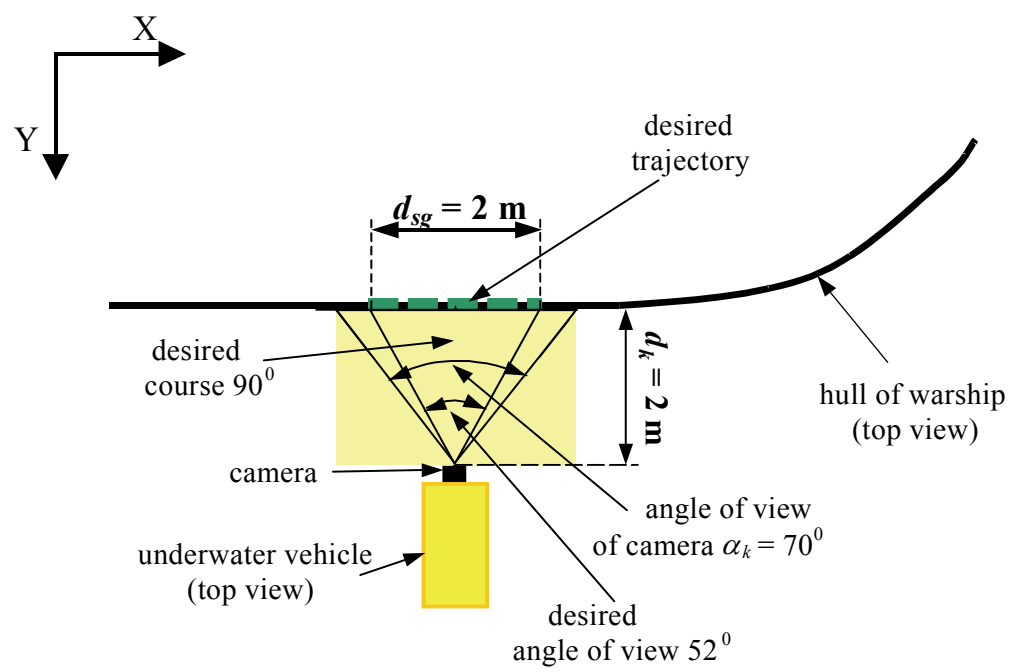

Fig. 8. Desired trajectory of Ukwial in vertical plane (top view)

From the fig. 8 results additional condition that a course of Ukwial should be controlled to the value of desired course $90^{\circ}$, what guarantees monitoring of whole underwater part of inspected hull.

Assuming that camera of an underwater vehicle is immovable and underwater vehicle moves along specified trajectory (fig. 7, fig. 8) following maximal errors of controlled parameters were calculated: maximal error in $X$ axis $\Delta x= \pm 0,4 \mathrm{~m}$, maximal error in $\mathrm{Y}$ axis $\Delta y= \pm 0,5 \mathrm{~m}$, maximal error of course $\Delta \psi= \pm 9^{\circ}$.

To illustrate changes of 4 parameters ( 3 coordinates and an angle of course) on single figure following method has been accepted (fig. 9): changes of a course at the discrete points of trajectory are presented as line segments covering with longitudinal axis of symmetry. Additionally direction of affecting sea current was visualized in form of a red arrow, what helps to illustrate conditions of moving in an underwater environment.

a) Trajectory of underwater vehicle in space $X Y Z$

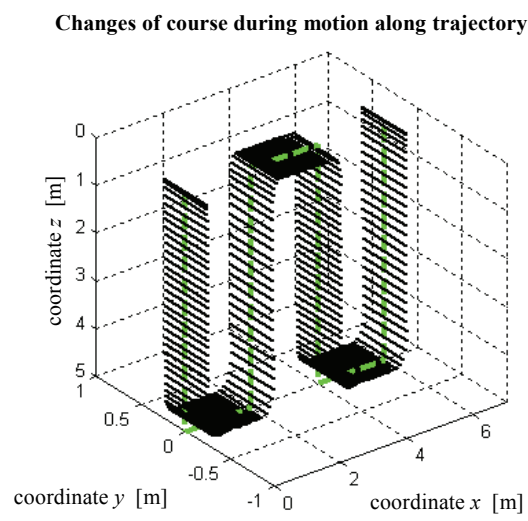


b) Trajectory of underwater vehicle in space $\mathrm{XYZ}$

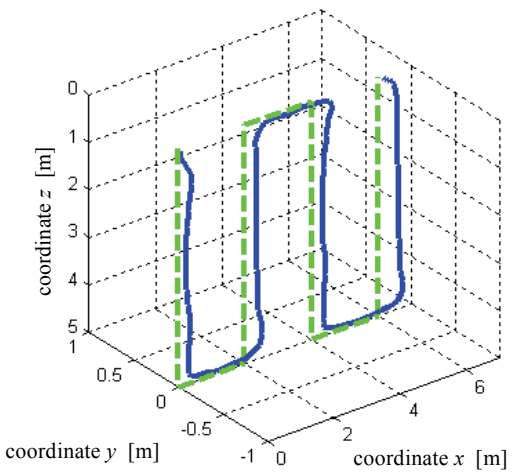

c) Trajectory of underwater vehicle in space XYZ

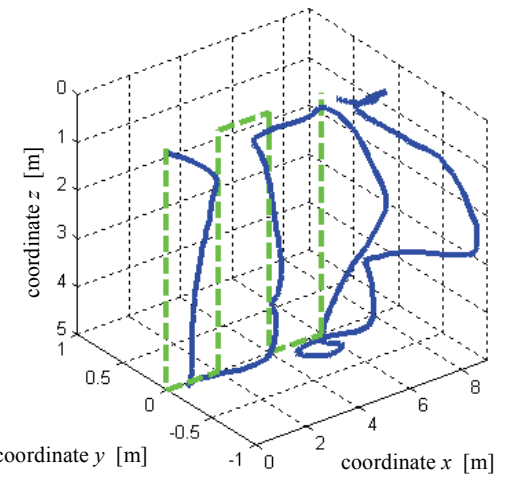

d) Trajectory of underwater vehicle in space XYZ

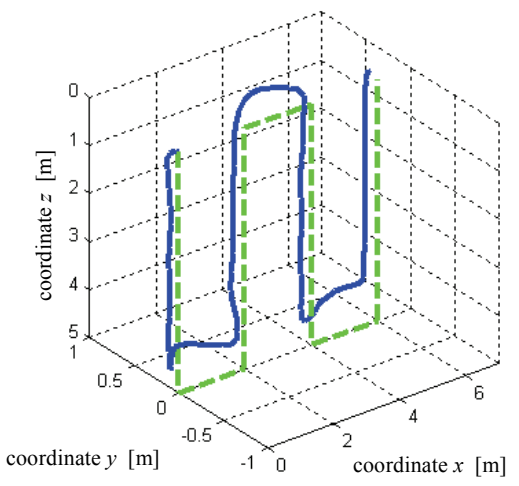

Changes of course during motion along trajectory

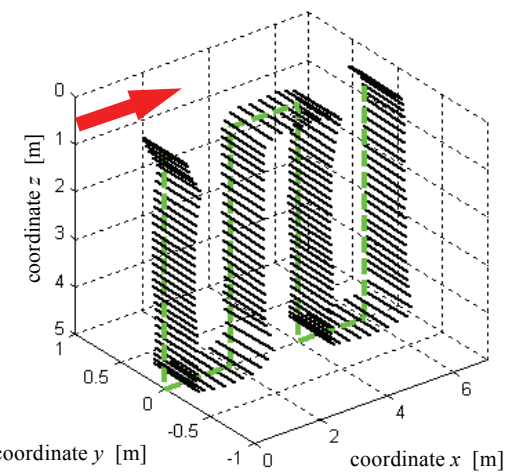

Changes of course during motion along trajectory

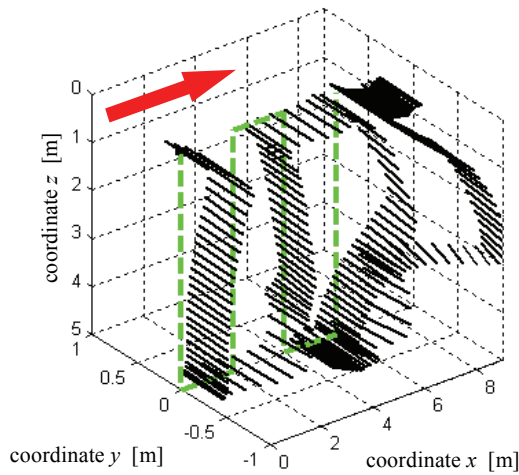

Changes of course during motion along trajectory

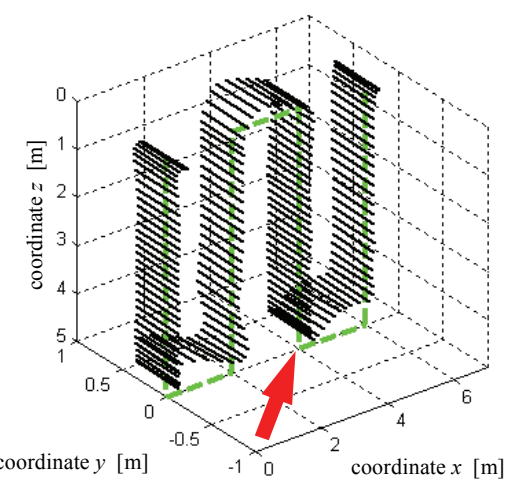

Fig. 9. Automatic steering of underwater vehicle along desired trajectory a) without sea current and with different sea currents: b) $\left.V_{p}=0,5 \mathrm{~m} / \mathrm{s}, \alpha_{p}=0^{0}, \mathrm{c}\right) V_{p}=0,9 \mathrm{~m} / \mathrm{s}, \alpha_{p}=0^{0}$ and d) $V_{p}=0,5 \mathrm{~m} / \mathrm{s}, \alpha_{p}=45^{0}$ 
On the base of achieved results of numerical researches (time diagrams presented on fig. 9 and direct and integral control quantity indexes included in (Szymak, 2004)) following partial conclusions have been found:

1. in the case of sea current does not affect, control system precisely controls movement of underwater vehicle along desired trajectory,

2. in the case of sea current affects, underwater vehicle is "pushed out" from desired trajectory with force depended on velocity of sea current in direction of affecting (for velocity $V_{p}=0,9 \mathrm{~m} / \mathrm{s}$ value of coordinate $y$ exceeds the maximal error in $\mathrm{Y}$ axis),

3. action of sea current affects also stabilization of a course (for velocity $V_{p}=0,9 \mathrm{~m} / \mathrm{s}$ value of a course exceeds the maximal error of course),

4. in other cases (below velocity $V_{p}=0,9 \mathrm{~m} / \mathrm{s}$ ) values of maximal errors are exceeded only in short time ( 1 or 2 second), what does not influence on quality of recorded video,

5. limitation of Ukwial control in the presence of stronger sea current (above $1 \mathrm{~m} / \mathrm{s}$ ) comes from limited value of thrust vector, which is generated by driving system.

\section{Comparison of simulation and experiment}

Experimental researches were carried out in the naval harbour Gdynia. Remotely operated vehicle Ukwial was launched from the warship "Flaming" (fig. 10). Computer simulation and experimental researches were executed without influence of sea currents. Selected results of computer simulations with influence of sea current have been presented in fig. 9 . While experimental researches taking into account affect of sea current have not been carried out yet.

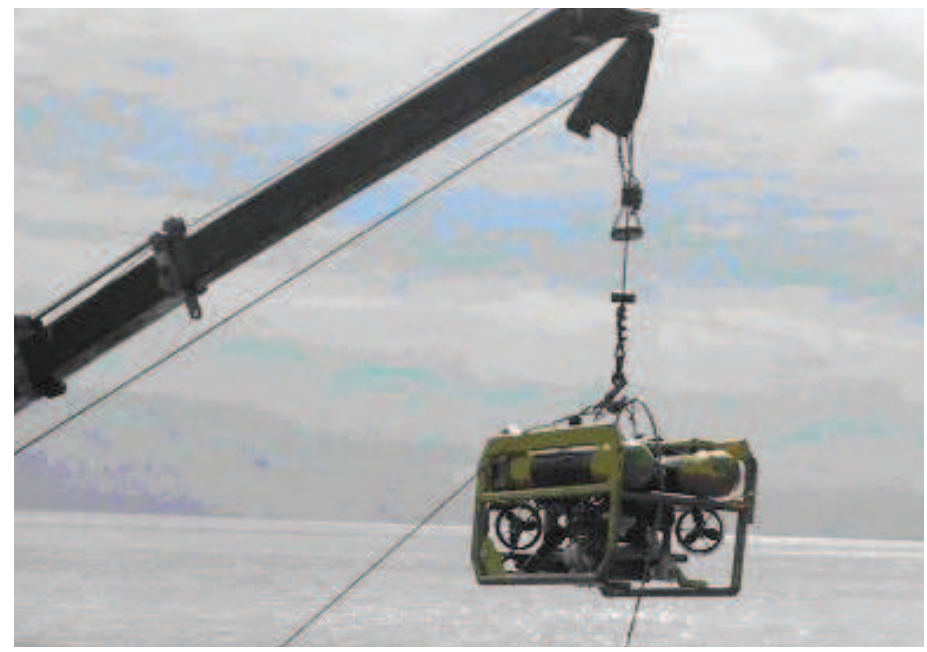

Fig. 10. Launching of remotely operated vehicle Ukwial

Selected results of course's fuzzy control have been presented on fig. 11. Results of other controller action have been inserted in (Szymak, 2004). Direct and integral indexes have been used to the evaluation of control quantity tested controllers. 


\section{EXPERIMENT}

a)

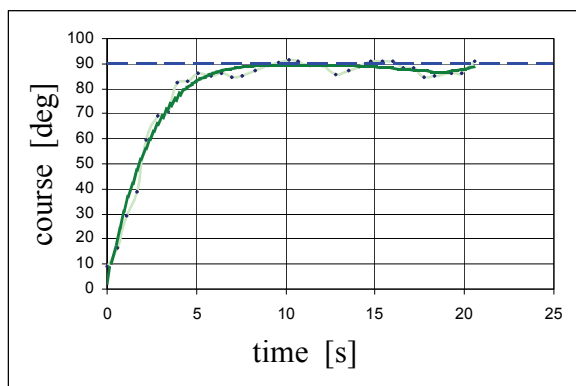

b)

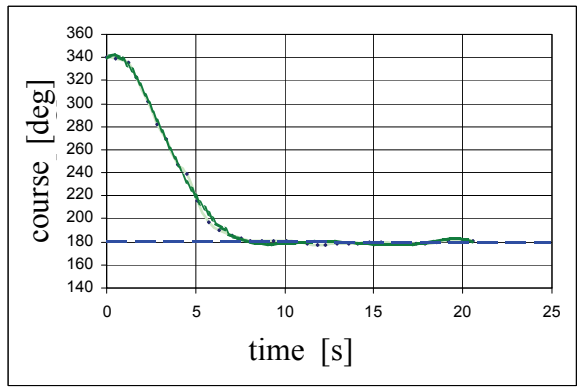

c)

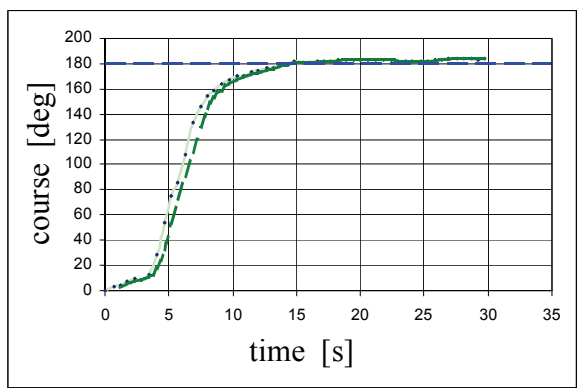

SIMULATION
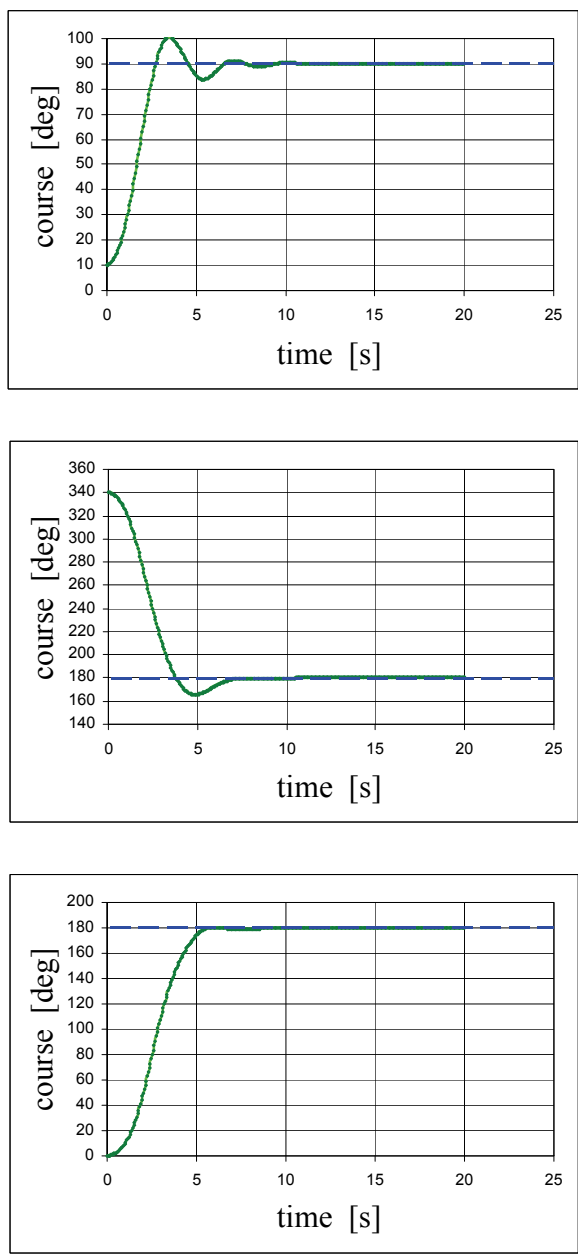

Fig. 11. Control of underwater vehicle's course: a) from initial value $10^{\circ}$ to set value $90^{\circ}$, b) from initial value $340^{\circ}$ to set value $180^{\circ}$, c) from initial value $0^{\circ}$ to set value $180^{\circ}$ with additional manoeuvre in $\mathrm{X}$ axis

Received results of researches allow to formulate the following conclusions for selected course FPD:

1. the better control quantity has been reached for underwater vehicle, which did not make additional manoeuvre; in that case total hydrodynamic thrust vector generated by propellers was used to change a course,

2. stabilizing influence of an umbilical cord on control of course can be observed on the base of experimental researches compare to oscillation achieved in simulation; it testifies that accepted model of an umbilical cord is not reliable,

3. designed course's controller carries out change of course $180^{\circ}$ in average time $10 \mathrm{~s}$. 


\section{EXPERIMENT}

a)

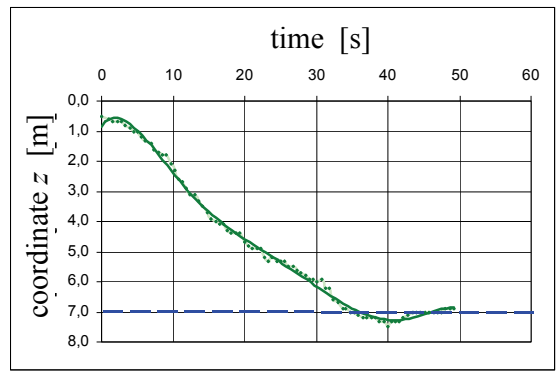

b)

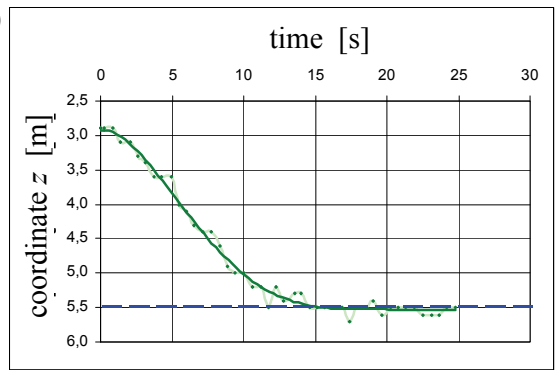

c)

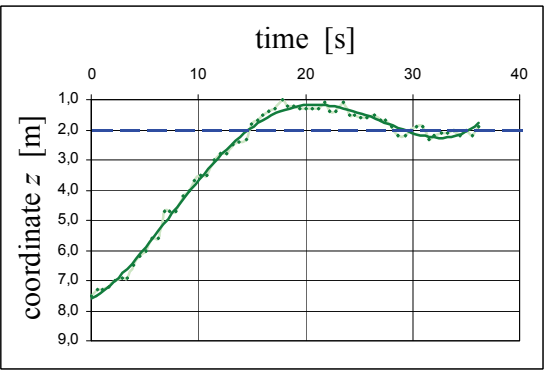

SIMULATION
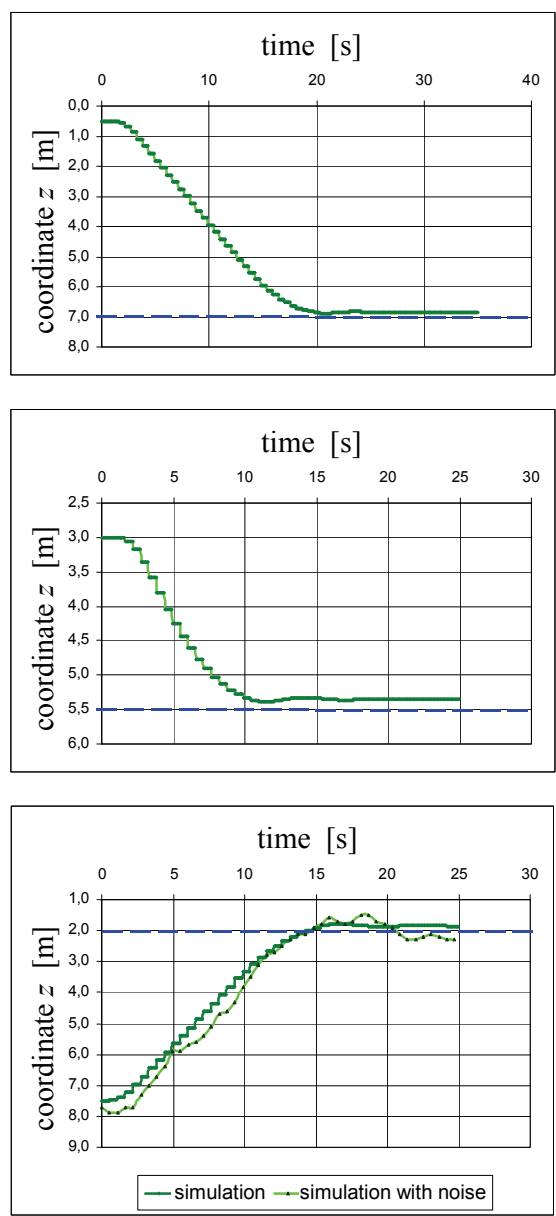

Fig. 12. Control of underwater vehicle's draught: a) from initial value $0,5 \mathrm{~m}$ to set value $7 \mathrm{~m}$, b) from initial value $3 \mathrm{~m}$ to set value $5,5 \mathrm{~m}$, c) from initial value $7,5 \mathrm{~m}$ to set value $2 \mathrm{~m}$ (additional simulation with noise)

During the experimental researches also draught's controller was verified correctly (fig. 12). On the base of received results it can be stated that:

1. signal coming from sensor of draught is less precise and has more added noise than signal of a course; it can be testified on the base of simulation with noise (curves received from experiment and simulation with noise are very similar, fig. 12c),

2. precise control of draught, which value is digitized with step $0,1 \mathrm{~m}$, is more difficult; the same control method gives worse results in control of draught than in control of course,

3. designed draught's controller carries out change of $1 \mathrm{~m}$ in average time $5 \mathrm{~s}$.

Unfortunately controllers of displacement in $X$ and $Y$ axis were not verified because of incorrect operation of underwater positioning system. 


\section{Conclusion}

Results of carried out numerical and experimental researches, which were presented partially in fig. 9, 11 and 12 confirmed that fuzzy data processing can be successfully used to steer the underwater vehicle with set values of movement's parameters.

Designed control system can be used to steer another underwater vehicles with different driving systems, because control signals were forces and moment of forces, which were processed to rotational speed of propellers with assistance of separate algorithm, specific for definite type of the underwater vehicle.

Positive verification of course's and draught's controllers enabled their implementation in the control desk of Ukwial.

Further researches should include: verification of controllers of displacement in $\mathrm{X}$ and $\mathrm{Y}$ axis, applying of other self-adopting to varying environmental conditions control methods.

\section{References}

Driankov, D.; Hellendoorn, H. \& Reinfrank, M. (1996). An introduction to Fuzzy Control, WNT, ISBN 83-204-2030-X, Warsaw, in Polish

Fossen, T. I. (1994). Guidance And Control Of Ocean Vehicles, John Wiley \& Sons Ltd., ISBN 978-0-471-94113-2, Norway

Garus, J. \& Kitowski, Z. (2001). Fuzzy Control of Underwater Vehicle's Motion, In: Advances in Fuzzy Systems and Evolutionary Computation, Mastorakis N., pp. 100-103, World Scientific and Engineering Society Press, ISBN 960-8052-27-0

Kubaty, T. \& Rowiński, L. (2001). Mine counter vehicles for Baltic navy, internet, http://www.underwater.pg.gda.pl/publikacje

Szymak, P. (2004). Using of artificial intelligence methods to control of underwater vehicle in inspection of oceanotechnical objects, PhD thesis, Naval Academy Publication, Gdynia, in Polish

Szymak, P. \& Małecki, J. (2007). Neuro-Fuzzy Controller of an Underwater Vehicle's Trim. Polish Journal of Environmental Studies, Vol. 16, No 4B, 2007, pp. 171-174, ISSN 12301485 


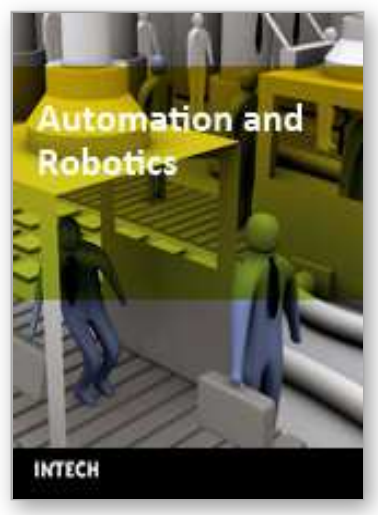

\author{
Automation and Robotics \\ Edited by Juan Manuel Ramos Arreguin
}

ISBN 978-3-902613-41-7

Hard cover, 388 pages

Publisher I-Tech Education and Publishing

Published online 01, May, 2008

Published in print edition May, 2008

In this book, a set of relevant, updated and selected papers in the field of automation and robotics are presented. These papers describe projects where topics of artificial intelligence, modeling and simulation process, target tracking algorithms, kinematic constraints of the closed loops, non-linear control, are used in advanced and recent research.

\title{
How to reference
}

In order to correctly reference this scholarly work, feel free to copy and paste the following:

Piotr Szymak and Jozef Malecki (2008). Control System of Underwater Vehicle Based on Artificial Intelligence Methods, Automation and Robotics, Juan Manuel Ramos Arreguin (Ed.), ISBN: 978-3-902613-41-7, InTech, Available from:

http://www.intechopen.com/books/automation_and_robotics/control_system_of_underwater_vehicle_based_o $\mathrm{n} \_$artificial_intelligence_methods

\section{INTECH}

open science | open minds

\section{InTech Europe}

University Campus STeP Ri

Slavka Krautzeka 83/A

51000 Rijeka, Croatia

Phone: +385 (51) 770447

Fax: +385 (51) 686166

www.intechopen.com

\section{InTech China}

Unit 405, Office Block, Hotel Equatorial Shanghai

No.65, Yan An Road (West), Shanghai, 200040, China

中国上海市延安西路65号上海国际贵都大饭店办公楼 405 单元

Phone: +86-21-62489820

Fax: +86-21-62489821 
(C) 2008 The Author(s). Licensee IntechOpen. This chapter is distributed under the terms of the Creative Commons Attribution-NonCommercialShareAlike-3.0 License, which permits use, distribution and reproduction for non-commercial purposes, provided the original is properly cited and derivative works building on this content are distributed under the same license. 